\title{
Original \\ Article \\ Projection of cancer incidence in five cities and cancer mortality in India
}

Marimuthu $\mathbf{P}$

Department of Biostatistics, National Institute of Mental Health and Neuro Science, Bangalore, India

Correspondence to: Dr. Marimuthu P, E-mail: marimuthu@nimhans.kar.nic.in

\begin{abstract}
BACKGROUND: Cancer is second largest non-communicable disease and it has a sizable contribution in the total number of deaths. It is important for the public health professionals to understand the dynamics of cancer incidence for future strategies. Therefore, this paper is attempted with the objective of projecting number of cancer incidence for five cities namely, Bangalore, Chennai, Delhi, Bhopal and Mumbai and to estimate the cancer mortality rate for all India for the year 2008. MATERIALS AND METHODS: The data were used from the Indian Council of Medical Research's publication of Population-Based Cancer Registry for the year 1999-2000. The population was calculated from the Census reports of 1991 and 2001. Causes-specific mortality report by the Central Bureau of Health Intelligence was used for estimating cancer mortality for all India. The age-specific rate method is utilized to project number of cancer incidence for the cities of Bangalore, Chennai, Delhi, Bhopal and Mumbai and to estimate cancer mortality in 2000 for all India. RESULTS AND CONCLUSION: About $26.6 \%$ increase is expected in the registered number of cancer cases in these five cities and $52.68 \%$ increase is projected for Delhi which would mean highest number of cases in Delhi among these five cities within a span of eight years. And in Mumbai it is expected to have a marginal decline in the number of cases for the year 2008 (around $-3.25 \%$ ). The age adjusted analysis indicates that Mumbai is experiencing the higher incidence rate among the five cities studied herein. It is estimated about $50 \%$ cancer mortality is reported from the age group 55 and above years.
\end{abstract}

Key words: Age-adjusted, cancer, incidence, projection, rates, standardized

\section{Introduction}

The changing demographic scenario in India is declining fertility level and increasing life expectancy. As the life expectancy at birth increases proportionately the percentage of geriatric population also rises. $\mathrm{H}$ igher incidence of non-communicable diseases, especially cancer is positively associated with percentage of aged population of a country. The World Cancer Report documents that cancer rates are set to increase at an alarming rate globally. Cancer rates could increase by $50 \%$ new cases for the year 2020. ${ }^{[1]}$ The Cancer Atlas published by Indian Council of Medical Research (ICMR) indicates that the age adjusted incidence of gall bladder cancer in women in $\mathrm{N}$ ew Delhi is $\mathbf{1 0 . 6}$ per 100000 population is the world's highest rate for women. From the same source it is reported that
Thyroid cancer is more prevalent in the coastal areas of Kerala and Karnataka. ${ }^{[2]}$

From the Population-based cancer registry data of 1982-84 it is demonstrated that the total number of incident cases in males could have increased (from 0.29 million) to 0.43 million and in females the incident cases of cancer could have increased (from 0.32) to 0.42 million by 2001. ${ }^{[3]}$ The increasing trend of cancer incidence has forced the humanity to work more on the cancer prevention and treatments. Therefore it is of importance to understand current incidence and trend

This paper was presented in the $I X^{\text {th }}$ Biennial Conference of International Biometric Society, conducted by Tuberculosis Research Center, Department of Biostatistics, Chennai -600031 , during $15^{\text {th }}$ to $17^{\text {th }}$ November 2007. 
of cancer for the planners and the policy makers to cope with the current/future situation. In this paper, an attempt is made for estimating the number of cancer incidence for the cities of D elhi, M umbai, Bhopal, Chennai and Bangalore. Since the mortality data due to cancer is lacking for the country, it is also attempted to estimate the cancer mortality for all India. And to identify the metropolitan city that experiences higher cancer incidence.

\section{Materials and Methods}

The data were used from the Indian Council of M edical Research's publication of Population-Based Cancer Registry for the year 1999-2000. Central Bureau of $\mathrm{H}$ ealth Intelligence $(\mathrm{CBHI})$ report on 'M ortality statistics in India 2006' was used for estimating cancer mortality. ${ }^{[4,5]}$ Population data for age-sex for the five cities Bangalore, Chennai, Delhi, Bhopal and Mumbai were obtained form the O ffice of Registrar General of India for two census year 1991 and 2001 and used for estimating the age-sex specific population for the year 2008 for the cities Bangalore, Chennai, D elhi, Bhopal and Mumbai. Population for the sixteen age groups that is 0-4, 5-9, 10-14, 15-19, 20-24, 25-29, 30-34, 35-39, 40-44, 45$49,50-54,55-59,60-64,65-69,70-74$, and 75+ were estimated by the exponential method for male and female population as on $M$ arch $1^{\text {st }} 2008$ as reference period. ${ }^{[6]}$

The age-specific rate method is utilized to project cancer incidence for all the 16 age groups for the metropolitan cities of Bangalore, Chennai, D elhi, Bhopal and M umbai. The age-specific rate method is utilized to project cancer incidence for all the 16 age groups for the metropolitan cities of Bangalore, Chennai, D elhi, Bhopal and M umbai. In the age specific rate method, population for each agesex group is estimated for the year 2008. Then most recently available cancer incidence rate is multiplied with estimated population for each age-sex group to get the number of new cases for the year 2008. The cancer incidence rate as multiplication factor was computed as the average of cancer incidence rates for the years 1999 and 2000 from the Population based Cancer Registry. The assumption of this method is that the population size and composition determine cancer incidence.

The population projection specific to age group, sex and city under consideration is obtained by modeling population growth as exponential function of time Specifically $\mathrm{Pt}=\mathrm{PO} \cdot \mathrm{e}^{\mathrm{r} \cdot \mathrm{t}}$ where $\mathrm{Pt}$ is population at year $t$. The projection for new years is then made by extrapolation of the model. To ensure that model estimates are stable and capture enough information, the population data of most recent census years (1991 and 2001) were used. For projecting the cancer incidence for the year 2008 the most recent incidence rate is multiplied with estimated population for the given agesex of place under consideration.

It is well known that direct standardization method is heavily depending on the standard population chosen. Therefore, for the purpose of comparison within five cities Bangalore, Chennai, Delhi, Bhopal and M umbai, all India population is estimated for the year 2000 and it is used as standard population for direct standardization method.

The office of the Central Bureau of $\mathrm{H}$ ealth Intelligence, Director General of $\mathrm{H}$ ealth Service, $\mathrm{M}$ inistry of $\mathrm{H}$ ealth and Family Welfare, $\mathrm{N}$ ew Delhi, has put up its endeavor to give some reliable estimated for the cause of deaths by age group for the country. They have used the data on $M$ edically Certified Cause of D eath for the country with the International Classification of D iseases (ICD)-Tenth Revision. Assuming that the reported trend of cause specific death rate is prevalent the country, total number of deaths was calculated, by multiplying estimated population by the crude death rate for the year 2000 . First male and female population for the age groups $0-4,5-14,15-54$ and 55+ and age not stated categories were calculated for the year 2000 then crude death rate is multiplied by 1000 and it is used as a multiplication factor for calculating number of deaths in 2000 . From the $\mathrm{CBH}$ I report, it is obtained that $\mathrm{N}$ eoplasm ( $\mathrm{COO}$ C14) deaths were 3.61 percentages. Therefore from the total deaths 3.61 percentage of deaths are considered as deaths due to cancer. Similarly weights for age-sex were calculated from the reported medically certified deaths. These weights were used for classifying total number of cancer deaths into age-sex categories.

\section{Results}

It is expected that around $26.6 \%$ of increase in the total number of cancer cases to be registered from these five cities for the year 2008 in the five cities studied herein. Table 1 shows that $D$ elhi is expected to have more number of registered cases (13920) followed by Mumbai (8505) for the same year. But in 2008, it is expected that Mumbai is likely to have a marginal decline $(-3.3 \%)$ in the cancer case to be registered in 2008. Bangalore and Chennai may have approximately equal number cases with a difference of few hundreds. From AAR shown in this table we may infer although $D$ elhi registry is showing more number of registration but the incidence rate is high in Mumbai.

Figure 1 depicts the male-age specific incidence cases. From the diagram we infer that males from $D$ elhi in the age group 65-69 may have more number of cases 
Table 1: Estimated number of cancer incidence and age adjusted rate by sex

\begin{tabular}{|c|c|c|c|c|c|c|c|c|}
\hline \multirow[b]{3}{*}{ Cities } & \multicolumn{4}{|c|}{ Number of incidence } & \multicolumn{4}{|c|}{ Age-adjusted rate } \\
\hline & \multicolumn{2}{|c|}{$\begin{array}{l}\text { Projected number of } \\
\text { cases for } 2008\end{array}$} & \multicolumn{2}{|c|}{$\begin{array}{c}\text { Average number of cases } \\
1999-2000 \text { by ICMR }\end{array}$} & \multicolumn{2}{|c|}{$\begin{array}{l}\text { Direct standardization } \\
2000 \text { (computed) }\end{array}$} & \multicolumn{2}{|c|}{$\begin{array}{l}\text { Direct standardization } \\
2000 \text { by ICMR }\end{array}$} \\
\hline & Male & Female & Male & Female & Male & Female & Male & Female \\
\hline Bangalore & 2262 & 2988 & 1742 & 2042 & 65 & 82 & 98 & 123 \\
\hline Chennai & 2296 & 2528 & 1980 & 2091 & 85 & 97 & 119 & 127 \\
\hline Delhi & 6815 & 7105 & 4588 & 4529 & 78 & 91 & 122 & 126 \\
\hline Bhopal & 701 & 554 & 476 & 424 & 60 & 61 & 120 & 110 \\
\hline Mumbai & 4170 & 4335 & 4440 & 4351 & 108 & 119 & 117 & 125 \\
\hline
\end{tabular}

Table 2: Estimated number of cancer mortality India (2000)

\begin{tabular}{lccc}
\hline & Males & Females & Total \\
\hline 0-4 years & 2253 & 1167 & 3420 \\
\hline 5 -14 years & 2492 & 1043 & 3535 \\
\hline 15-54 years & 36547 & 27214 & 63761 \\
\hline $55+$ years & 53990 & 28449 & 82439 \\
\hline Age NA & 2686 & 1327 & 4013 \\
\hline Total & 97968 & 59200 & 157168 \\
\hline
\end{tabular}

followed by the age group 60-64 for the year 2008 . Then the males from Chennai will have an increasing trend from the age of 50 to 69 years. Almost a similar trend of cancer incidence for males in the year 2008 is expected from Chennai, Bangalore and M umbai.

In Figure 2, female-age specific incidence cases is shown. This figure indicates that females from Delhi in the age group 50-54 may have more number of cases followed by the age group 40-44 for the year 2008. Then the females from Bangalore may have more number of cases from the age of 45 to 54 years. Almost a similar trend of cancer incidence for females in the year 2008 is expected from Chennai, Bangalore and Mumbai.

Table 2 gives the evidence that the estimated cancer mortality for the year 2000 had been 157168, for the year 2000, around 97968 and 59200 male and female cancer deaths respectively for the same year. And it was $3.61 \%$ of cancer deaths to the total deaths in the year 2000 . From this table, it is estimated about $50 \%$ cancer mortality is reported from the age group 55 and above years.

\section{Discussion}

Although there is no variation in reported number of cases from Mumbai over the years, the standardization

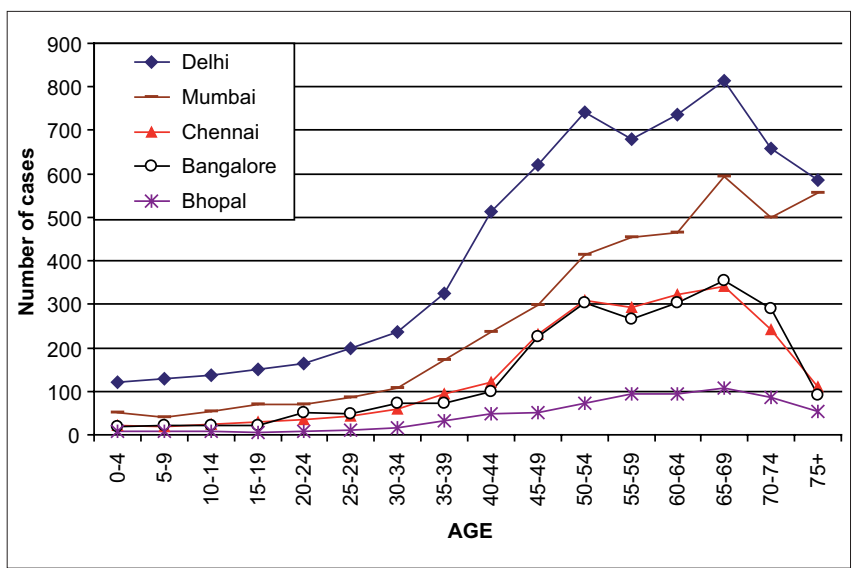

Figure 1: Estimated cancer incidence of males in five cities 2008

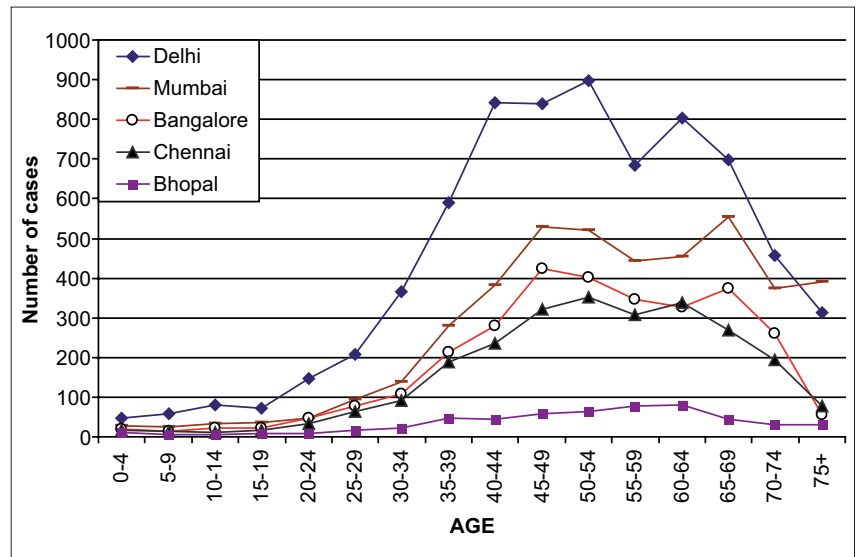

Figure 2: Estimated cancer incidence of females in five cities 2008

gives the idea of higher incidence rate for M umbai. After further analysis on the population data, it is found that the Mumbai population is negatively growing from 1991 to 2001 census years, but the registered number of case is constant over the years. The decreasing population size in Mumbai and almost the same number of registered cancers cases over the years influenced the incidence rate in M umbai. The observed age-adjusted 
rates (as given in the ICMR report) for these cities do not have much difference. The purpose of age adjusted rate (AAR) by direct standardization method adopted in the Population Based Cancer Registry is comparing the incidence rate with other cities across the globe. Therefore, in the Population-Based Cancer Registry's report, international population structure is considered as standard for the standardization purpose. O ne of the objectives of this article is to compare the incidence rate within Bangalore, Chennai, D elhi, Bhopal and Mumbai and hence all India population for the year 2000 is taken as standard population. The computed AAR clearly indicates that the incidence rate in $M$ umbai is high among these five cities.

In the recent trend it is observed that there is decline in the cervical cancer incidence, but this decline is very meager. ${ }^{[7]}$ Though the cancer incidence rate in India is less than that of the Western countries but due to the large population size, number of cases is more prevalent at any time. ${ }^{[8]}$ It is shown that in India 8.7 million Disease Adjusted Life Years lost from cancer was second to ischaemic heart disease. ${ }^{[9]}$ Gupta and R oy have given the account of Tobacco-related cancers in India. They have demonstrated that tobacco is one of the major risk factors for various types of cancers and the population using tobacco is more in India, as a result, the tobaccorelated cancers are also increasing year by year. ${ }^{[10]}$ Cancer registries have a common goal of recording all the cancer cases but for various reasons the reports are delayed. A statistical model is presented for a correction in the delayed reporting of cancer incidence. ${ }^{[11]}$ The cancer incidence among migrated population, BritishColumbia, Indio-Canadian men women differ from the Indian population. ${ }^{[12]}$ If the vital registration system is complete and it covers to a great extent only then can one rely on the registration system. But till now there is no satisfactory level of registration. $N$ ot only in India, but in almost all the developing countries, cause-specific mortality data is seldom available. Therefore, Public health personnel and policy makers mainly depend on the cancer registry data.

In conclusion, it is found that Delhi is expected to have more number of cases every year. Though the number of cases is marginally declining in Mumbai, it is experiencing higher incidence rate among these five cities. More number of cases are projected in the age group 45-55 and in the age group of 65-70 years for females and males respectively. Cancer deaths are about $3.6 \%$ to the total deaths and $50 \%$ cancer deaths are recorded from the age group 55 and above categories.
For estimating the number cancer mortality Central Bureau of $\mathrm{H}$ ealth Intelligence $(\mathrm{CBHI})$ report on 'M ortality statistics in India 2006' was used. As declared by $\mathrm{CBHI}$, this report is complete for 14.5 percentages. But, assuming that the reported trend of cause-specific death rate is prevalent in the country, the total number of cancer deaths were estimated. So that the estimated number of deaths may be considered as minimum expected number of cancer deaths for the country. The limitation on the projected number of cancer incidence is that only the population dynamic is taken in to account while projecting the number of cases for these five cities. But, it is assumed that disease dynamic is not going to significantly change within the time period studied. Obviously, cancer projections can never be as accurate as actual cancer registrations. R evisions will vary due to the dynamic nature of the registries' database and changing population projection methods. Accurate estimation depends on many factors such as report figures, the way in which the data is collected and compiled, the method of diagnosis and the reporting mechanism.

\section{References}

1. WHO. International Agency for Research on Cancer. World Cancer Report, 2003.

2. Development of an atlas of cancer in India. National Cancer Registry Progamme. New Delhi: Indian Council of Medical Research; 2004.

3. Murthy NS, Juneja A, Sehgal A, Prabhakar AK. Cancer projection by the turn of century - Indian Scene. Indian J Cancer 1990;27:74.

4. Two year report (1999-2000) of the population based cancer registries. National Cancer Registry Programme. New Delhi: Indian Council of Medical Research; 2005.

5. Mortality Statistics in India. Status of Mortality Reporting in India. Central Bureau of Health Intelligence. Directorate General of Health Services. Ministry of Health and Family Welfare. New Delhi: Nirman Bhavan; 2006.

6. Census of India. New Delhi: Registrar General of India; 2001.

7. Murthy NS, Chaudhry K, Saxena S. Trends in cervical cancer incidence-Indian scenario. Eur J Cancer Prev 2005; 14:513-8.

8. Krishnan Nair M, Sankaranarayanan R. Epidemiological lead to cancer control. Cancer Causes Control 1991;2:263-5.

9. Sarin R. Indian national cancer control programme: Setting sight on shifting targets. J Cancer Res Therap 2005;1:240-8.

10. Gupta PC, Cecily, Roy S. Tobacco related Cancers - Its impact on Health economy. Health Administrator 2005; 17:85-92.

11. Dougles N. Midthune, Michale P, Fay, Limin X, Clegg et al. Modeling reporting delays and reporting correction in cancer registry data. J Am State Assoc 2005; 100:61-70.

12. Hislop TG, Bajdik CD, Saroa SR, Yeole BB, Barroetavena MC. Cancer Incidence in Indians from three areas: Delhi and Mumbai, India, and British Columbia, Canada. J Immigr Minor Health 2007; 9:221-7.

Source of Support: Nil, Conflict of Interest: None declared. 